\title{
NOTE
}

\section{Canine mesenchymal stromal cell-conditioned medium promotes survival and neurite outgrowth of neural stem cells}

\author{
Michi NAKAMURA ${ }^{1) \#, ~ H i d e t a k a ~ N I S H I D A ~}{ }^{2) \# *}$, Karin YOSHIZAKI ${ }^{2)}$,

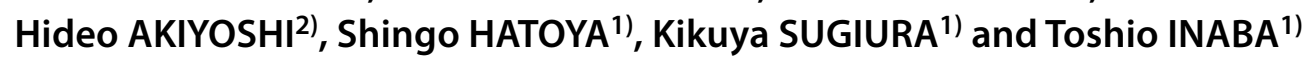 \\ ${ }^{1)}$ Department of Advanced Pathobiology, Graduate School of Life and Environmental Sciences, \\ Osaka Prefecture University, 1-58 Rinku Ourai Kita, Izumisano, Osaka 598-8531, Japan \\ 2) Department of Advanced Clinical Medicine, Graduate School of Life and Environmental Sciences, \\ Osaka Prefecture University, 1-58 Rinku Ourai Kita, Izumisano, Osaka 598-8531, Japan
}

\section{J. Vet. Med. Sci. \\ 82(5): 668-672, 2020 \\ doi: 10.1292/jvms.19-0141}

Received: 13 March 2019

Accepted: 18 March 2020

Advanced Epub: 6 April 2020
ABSTRACT. We examined the paracrine action of canine mesenchymal stromal cells (MSCs) derived from bone marrow on the survival and differentiation of neural stem cells (NSCs) in vitro. MSCs were collected from the proximal end of the diaphysis of femur of healthy beagle dogs. The $70-80 \%$ confluent MSCs were re-fed with serum-free DMEM. The MSCs were incubated for $48 \mathrm{hr}$ and the supernatant was collected as the conditioned medium (MSC-CM). The survival rate of NSCs in MSC-CM was significantly greater than in the medium without MSC-CM. The percentage of differentiated neurons and neurite length in MSC-CM was also significantly higher than in the medium without MSC-CM. These results suggested that canine MSC-CM promotes stem cell survival and neural differentiation of NSCs.

KEW WORDS: conditioned medium, dog, mesenchymal stromal cell, neural differentiation

Mesenchymal stromal cells (MSCs) are plastic-adherent, spindle-shaped cells that express CD44, CD73, and CD90 and lack expression of the CD34 and CD45 $[4,16]$. They secrete various trophic factors that support the healing process including suppressing inflammation and promoting tissue regeneration [2, 19]. Several studies [6, 11, 17] in rodent models have shown that intravenous or intrathecal injection of MSCs promotes functional recovery from traumatic brain injury (TBI) and spinal cord injury (SCI). MSCs are expected to be useful for clinical application in regenerative medicine in dogs. There have been several clinical trials of MSCs for SCI in dogs [14, 15, 20]. Injection of autologous MSCs caused no complication [14, 15], and some dogs with severe SCI improved their motor function after intrathecal or intramedullary MSC injection [14, 15].

Some transplanted MSCs attached themselves to the spinal cord near the surface, with a few invading the lesion in rodent SCI model. They promoted tissue repair and functional recovery in rats with SCI $[17,26]$. MSC transplantation could be a promising treatment for tissue repair. However, the cells take long time to proliferate and alternative technique which can use immediately is required $[14,15]$. The MSC-conditioned medium (MSC-CM), which is easily preserved by freezing, is convenient for immediate application. The MSC-CM promote functional recovery after rat-SCI [12]. The cell-free therapies resolve several safety considerations potentially associated with the transplantation of living cells including tumorigenesis, emboli formation, immune compatibility, and transmission of infections [25].

Human and rodent MSCs secrete various types of growth factors and promote neuronal survival and neurite outgrowth of neural stem cells (NSCs) in vitro [7, 10]. Recently, it was reported that endogenous NSCs exist in the central canal of mammalian spinal cord [9]. These cells play key roles on regeneration of damaged neurons. There was no data describing paracrine action of canine MSCs for the promotion of survival and neural differentiation of NSCs. The aim of the present study was to investigate whether canine MSC-CM suppressed the cell death and promotes neural differentiation of NSCs derived from monkey-derived embryonic stem cells (ESCs).

Samples of bone marrow were collected from 5 Beagles aged between 4 and 8 years under sterile conditions. All procedures, and the postoperative care of animals, were in accordance with the guidelines of Osaka Prefecture University (No. 21-65). Bone marrow fluid was collected under anesthesia using of 13-gauge Jamshidi needles (Allegiance Healthcare, McGaw Park, IL, USA) from the proximal end of the diaphysis of the femur, into sterilized 10-m $l$ syringes containing 2,000 U heparin (Novo Heparin 1000, Hoechst Marion Roussel, Tokyo, Japan).

\footnotetext{
${ }^{*}$ Correspondence to: Nishida, H.: hnishida@vet.osakafu-u.ac.jp

\#These authors contributed equally to this work.

(O2020 The Japanese Society of Veterinary Science
}

This is an open-access article distributed under the terms of the Creative Commons Attribution Non-Commercial No Derivatives (by-nc-nd) License. (CC-BY-NC-ND 4.0: https://creativecommons.org/licenses/by-nc-nd/4.0/) 
The bone marrow perfusate were suspended in $15 \mathrm{~m} l$ Dulbecco's phosphate buffered saline (D-PBS, Nakalai Tesque, Kyoto, Japan). The mononuclear cells were isolated by density centrifugation with a lymphocyte separation solution (Nakarai Tesque) at $400 \times \mathrm{g}$ for $30 \mathrm{~min}$ at room temperature (approximately $20^{\circ} \mathrm{C}$ ). The buffy coat at the interface was collected, mixed with $20 \mathrm{ml}$ $\mathrm{D}$-PBS, and centrifuged at $400 \times \mathrm{g}$ for $5 \mathrm{~min}$. The precipitated cells were washed twice with D-PBS. The number of cells was determined with a hemacytometer. Enriched mononuclear cells were plated in $25-\mathrm{cm}^{2}$ tissue culture flasks (AGC Technoglass, Shizuoka, Japan) at a density of $1.5 \times 10^{5} \mathrm{cells} / \mathrm{cm}^{2}$ in DMEM (Nakalai Tesque) containing 10\% fetal bovine serum (FBS, PAA Laboratories, Pasching, Austria) and $1 \%$ antibiotic-antimycotic solution (Nakalai Tesque), with incubation at $37^{\circ} \mathrm{C}$ in a humidified $5 \%$ carbon dioxide environment. Nonadherent cells were removed by replacing the medium $48 \mathrm{hr}$ after plating. The culture medium was changed 3 times per week. After 14 days, the adherent MSCs were transferred to another culture at a concentration of $8.0 \times 10^{3}$ cells $/ \mathrm{cm}^{2}$ (passage 1). The 70-80\% confluent MSCs were re-fed with serum-free DMEM. The MSCs were incubated for $48 \mathrm{hr}$ and the supernatant was collected and centrifuged at 2,000 $\mathrm{g} \times 10 \mathrm{~min}$. The supernatant was viewed as MSC-CM. $10 \mathrm{ml}$ of MSC-CM were frozen at $-80^{\circ} \mathrm{C}$ for $1-3$ months.

Flow cytometric analysis was performed to evaluate MSC surface markers. Cells (passage 1) were detached from the flasks with $0.05 \%$ trypsin and $0.53 \mathrm{mM}$ EDTA and were collected by centrifugation. Aliquots containing $1.5 \times 10^{5}$ cells were washed in fluorescence-activated cell sorting buffer (D-PBS containing $0.5 \%$ FBS and $0.1 \%$ sodium azide), and were incubated for 30 min on ice in $100 \mu \mathrm{l}$ of fluorescence-activated cell sorting buffer with fluorescent isothiocyanate and fluorescent-labeled antibodies for CD34 (1/25, PE Mouse Anti-Dog CD34, Becton Dickinson Bioscience, Franklin Lakes, NJ, USA), CD44 (1/50, PE Rat Anti-Mouse CD44, Becton Dickinson Bioscience), CD45 (1/10, Fluorescent isothiocyanate Rat Anti-Dog CD45, Becton Dickinson Bioscience), and CD90 (1/50, Rat Anti-Dog Thy-1, AbD Serotec, Oxford, UK). Isotype control was used in a negative control sample. Data were analyzed by recording 10,000 events on a flow cytometer (FACSCalibur with Cell Quest software, Becton Dickinson Bioscience).

The cynomolgus monkey-derived ESCs, named CMK6, [23] were obtained from Dr. Tsuyoshi Okuno (Tanabe Mitsubishi Pharma Corp.). CMK6 were differentiated into NSCs, as described by Okuno et al. [18]. In summary, CMK6 colonies were transferred into non-adhesive bacteriological dishes in the conditioned medium collected from rat primary-cultured astrocytes supplemented with $20 \mathrm{ng} / \mathrm{m} l$ of fibroblast growth factor (FGF)-2 (R\&D Systems, Minneapolis, MN, USA). These colonies were cultured for 10 days, giving rise to spheres, which were then plated onto dishes coated with poly-L- Lysine/Laminin (SigmaAldrich, St. Louis, MO, USA), and were cultivated for 7 days in Neurobasal medium (Invitrogen, Carlsbad, CA, USA) supplied with B27 supplement (Invitrogen), $20 \mathrm{ng} / \mathrm{m} l \mathrm{FGF}-2$, and $20 \mathrm{ng} / \mathrm{m} l$ recombinant epidermal growth factor (EGF, R\&D systems, NSCM). The spheres attached onto the dishes and formed circular cluster of cells. These cells migrated from the clusters to surrounding areas. The centers of the clusters containing undifferentiated ES cells were removed with a glass capillary, and the rest of the cells covered the growth surface of the dish in circular monolayer. These differentiated cells were used as CMK6 NSCs.

CMK6 NSCs $\left(1.1 \times 10^{5}\right.$ cells) were plated onto poly-D-Lysine/Laminin (Sigma-Aldrich) coated 24-well plate (AGC Technoglass), and were cultured in MSC-CM or DMEM without FBS (non-CM). Apoptosis, neuronal differentiation, and neurite elongation of NSCs were investigated. Apoptosis was assessed after Hoechst 33342 (Sigma-Aldrich) staining in order to characterize nuclear morphology. In summary, after undergoing in MSC-CM or non-CM for $48 \mathrm{hr}$, the cells were stained with $5 \mu l$ l $\mathrm{m} l$ of Hoechst 33342 for $30 \mathrm{~min}$. Live cells have a smooth, round nucleus characterized by faint staining. The number of apoptotic cells was assessed by counting Hoechst 33342 stained cells with condensed and fragmented nuclei in 500 cells per well at a magnification of $\times 200$ under a fluorescent microscope (C1Si, Nikon, Tokyo, Japan).

After culturing in MSC-CM or non-CM for 10 days, the differentiation of NSCs to neurons and neurite length were assessed using Image J (U. S. National Institutes of Health, Bethesda, MD, USA). The medium was discarded and the cells were rinsed twice with D-PBS. The cells were fixed with $4 \%$ paraformaldehyde for 10 min and then immersed in PBS containing $0.1 \%$ bovine serum albumin and $0.1 \%$ Triton X-100. Non-specific binding was blocked by incubation for 30 min at room temperature with PBS containing $10 \%$ bovine serum albumin. The slides were incubated further in the presence of the following antibodies separately: tubulin $\beta 3$ isoform (Tuj1) (1:1,000, Millipore) as immature neuron marker; glial fibrillary acidic protein (GFAP) (1:1,000, Millipore) as astrocyte marker. The cells were washed and then incubated in Alexa Fluor 488- and Alexa Fluor 546-labeled secondary antibodies (1:1,000, Invitrogen). Cells were mounted in Vecta-shield containing 4,6-diamidino-2-phenylindole (DAPI; Vector Laboratories, Burlingame, CA, USA) and analyzed under a fluorescence microscope equipped with phase-contrast optics. For quantification, a percentage of Tuj 1 positive cells were counted in 8 randomly selected fields per well at a magnification of $\times 100$. The length of axons was measured in 8 randomly selected fields per well at a magnification of $\times 100$ and averaged using Image $\mathrm{J}$.

Data were presented as mean \pm SEM. Values were compared using the un-paired $t$-test between 2 groups. The apoptosis rate of NSCs was analyzed via a Fisher exact test. All analyses were performed with statistical analysis software (Graphpad Prism software, La Jolla, CA, USA). Values of $P<0.05$ were considered significant.

The cells were adherent to the plastic dishes after seeding the mononuclear cells from the bone marrow. The cells were cultured 14 days after seeding of the mononuclear cells and were passaged. More than 95\% of cells were CD44 and CD90 positive and negative for CD34 and CD45, as described previously [17]. After the cells were $70-80 \%$ confluent, they were cultured with DMEM without FBS for $48 \mathrm{hr}$, and MSC-CM was collected.

Next, the CMK6 were differentiated into NSCs. The NSCs were cultured in MSC-CM and non-CM for 48 hr, and the percentage of apoptotic cells among all cells cultured in MSC-CM and non-CM was assessed (Fig. 1A and 1B). The percentage of apoptotic cells cultured in MSC-CM (33.1\%) was significantly lower than for cells cultured in non-CM (54.5\%; Fig. 1C, $P<0.01)$. NSCs were cultured in non-CM, more than $95 \%$ of NSCs differentiated into astrocytes (Fig. 2A). In MSC-CM, NSCs were differentiated into Tuj-1 positive neural cells and astrocytes (Fig. 2B). The percentage of Tuj1 positive cells cultured in MSC-CM (16.0\%) was 

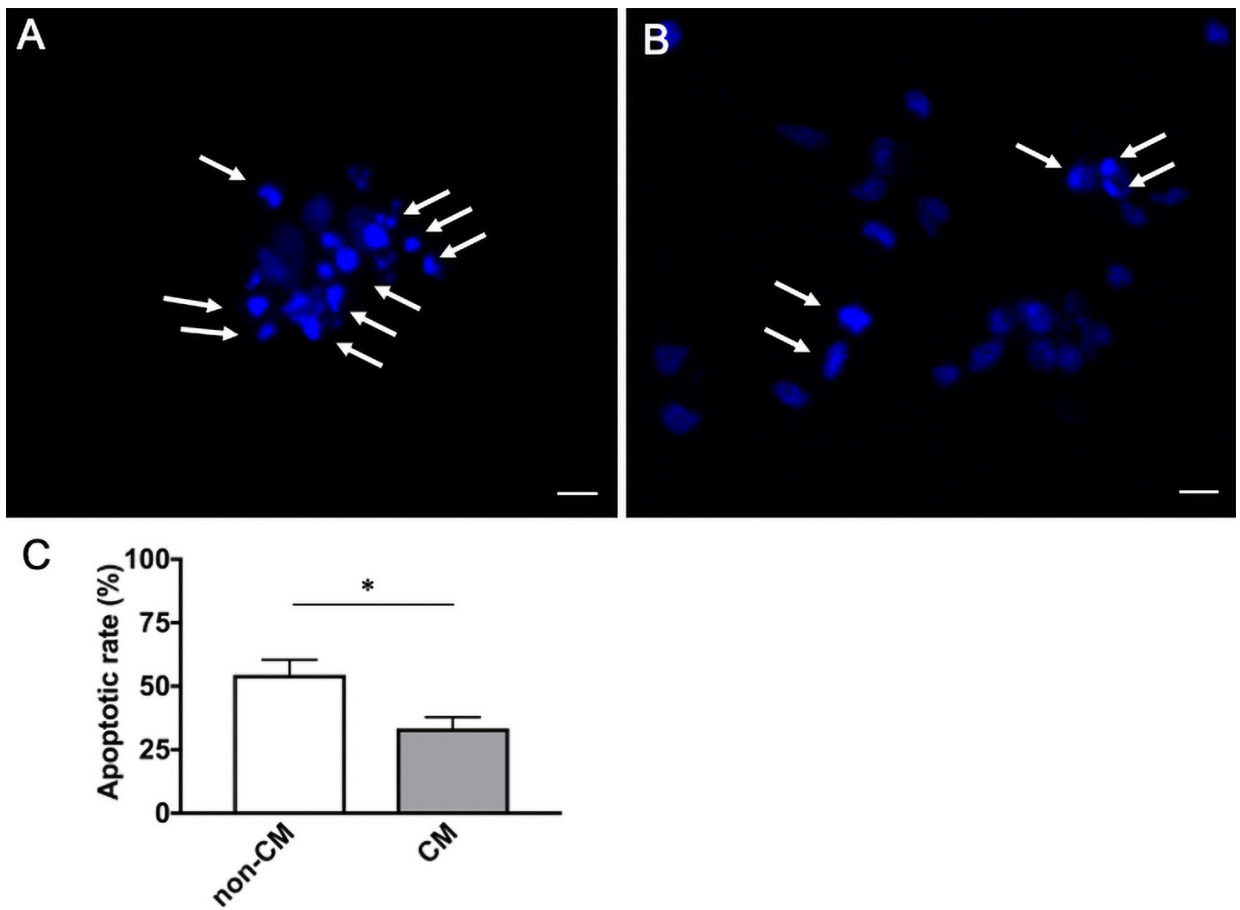

Fig. 1. Nuclear staining of neural stem cells (NSCs) with Hoechst 33342. Photomicrographs of NSCs after culturing in non-conditioned medium (non-CM) (A) or mesenchymal stromal cell-conditioned medium (MSC-CM) (B) for $48 \mathrm{hr}$. Arrow marks indicate apoptotic cells (Scale bar=10 $\mu \mathrm{m}$ ). Bar graph showing the percentages of apoptotic NSCs cultured in MSC-CM or non-CM (C). The percentage of apoptotic cells cultured in MSC-CM was significantly lower than for cells cultured in non-CM $(P<0.01)$.
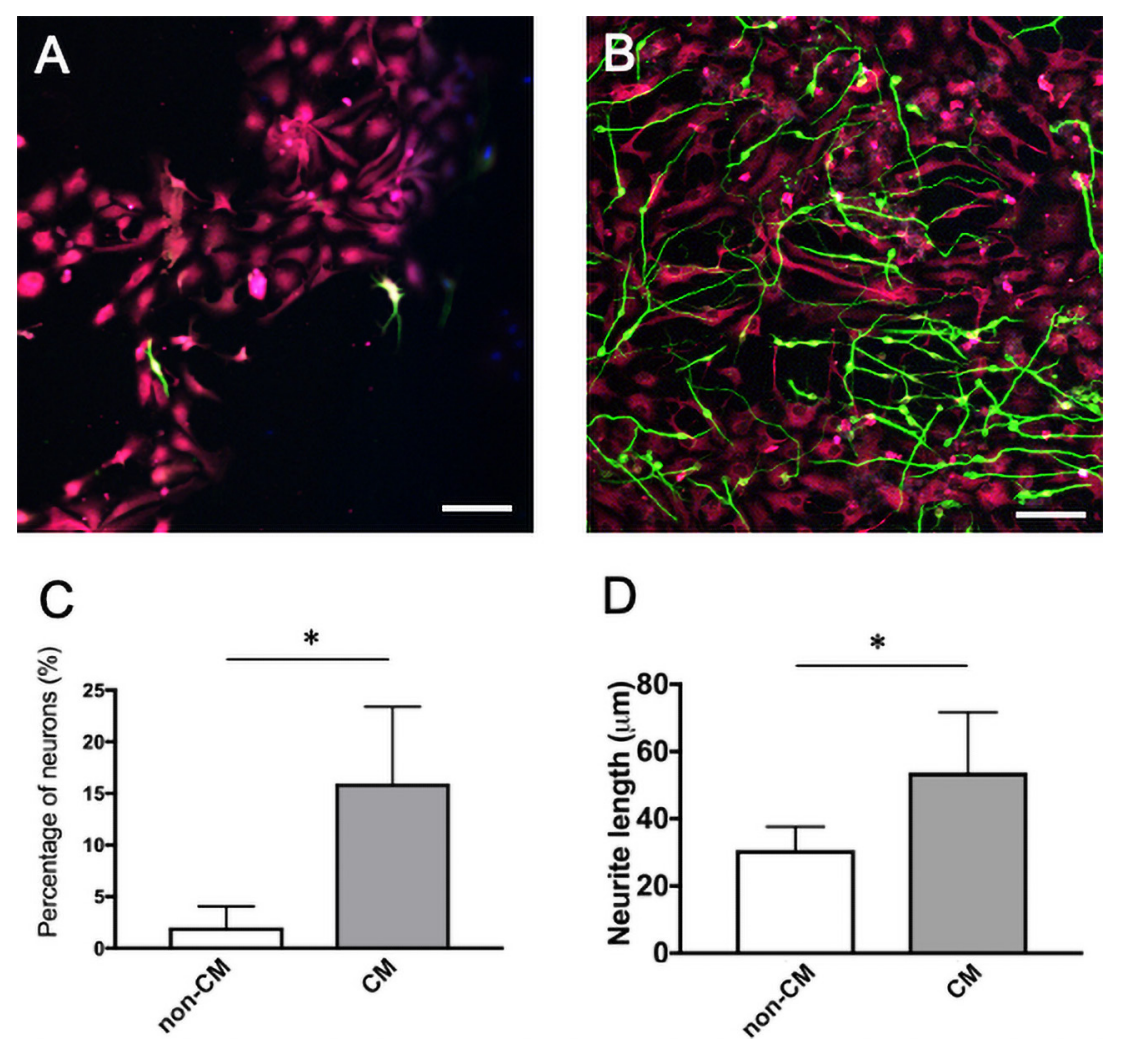

Fig. 2. Immunohistochemical detection of neurons and astrocytes during neural stem cells (NSC) differentiation. Photomicrographs of immunocytochemical staining for glial fibrillary acidic protein (GFAP) (red) and tubulin $\beta 3$ isoform (Tuj1) (green)-visualized neurite outgrowth cultured in the non-CM (A) or MSC-CM (B) for 10 days. Bar graphs showing the percentage of Tuj1 positive cells (C). The percentage of Tuj1 positive cells cultured in MSC-CM was significantly higher than with non-CM $\left({ }^{*} P<0.01\right)$. Bar graphs showing quantitative analysis of neurite outgrowth of NSCs (D). The neurite length in MSC-CM was significantly greater than non-CM $(* P<0.01)$. 
significantly higher than in non-CM (2.0\%; Fig. $2 \mathrm{C}, P<0.01)$. The neurite length of cells cultured in MSC-CM (53.8 $\mu \mathrm{m})$ was significantly longer than in non-CM $(31.9 \mu \mathrm{m}$; Fig. 2D, $P<0.01)$.

Several studies have found that human and rodent MSCs promote survival and neurite elongation of neural cells in vitro [3, 13, 24, 28]. A high percentage of mouse ES cells were differentiated into dopaminergic neurons by coculturing with MSCs [5]. Our finding is that MSC-CM enhanced survival of NSCs and promoted neural differentiation of NSCs into neuronal phenotype. These findings are similar to those found in studies using rat or human MSCs [10, 22]. Previous report showed that canine MSC-CM increased human neuroblastoma differentiation and neurite outgrowth in vitro [1]. MSC-secreted growth factors, including nerve growth factor, brain-derived neurotrophic factor, hepatocyte growth factor, transforming growth factor $\beta$-1, insulin-like growth factor, and vascular endothelial growth factor, promoted the survival and neural differentiation of NSCs [2, 19]. A further report has found that human MSCs facilitated survival of neurons through the transfer of mitochondria [8]. Extracellular vesicles (EVs) contain a diverse cargo, including proteins, mRNA, micro RNA, and mitochondria. MSC-derived EVs contributed to neurite outgrowth [27]. MSCs are therefore able to support neural tissue through multiple functions.

MSC-derived products would effectively mimic the therapeutic effects of MSCs. In addition, large-scale production of cell-free products is possible by repeated harvesting of MSC-CM. Another advantage is that MSC-CM can easily preserved by freezing without the need for cryopreservatives for a long term period without loss of product potency [25]. The off-the-shelf secretome therapies could be immediately available for treatment of acute condition [25]. Use of MSC-CM potentially resolve safety consideration associated with transplantation of cells including immune compatibility and tumorigenicity.

There was no establishment of canine ESCs or induced pluripotent stem cells at this time [21], and monkey ESCs were therefore used for in vitro assay. A limitation of the present study is that any species-specific response was not considered. Further studies are needed to assess the effect of MSCs with the use of NSCs derived from dogs. We do not have evidence that canine MSC-CM improve locomotor function in SCI model. Further studies are needed to determine which neurotrophic factors from canine MSC promote the survival and neurite elongation of neural cells.

\section{REFERENCES}

1. Al Delfi, I. R., Sheard, J. J., Wood, C. R., Vernallis, A., Innes, J. F., Myint, P. and Johnson, W. E. 2016. Canine mesenchymal stem cells are neurotrophic and angiogenic: An in vitro assessment of their paracrine activity. Vet. J. 217: 10-17. [Medline] [CrossRef]

2. Chen, X., Katakowski, M., Li, Y., Lu, D., Wang, L., Zhang, L., Chen, J., Xu, Y., Gautam, S., Mahmood, A. and Chopp, M. 2002. Human bone marrow stromal cell cultures conditioned by traumatic brain tissue extracts: growth factor production. J. Neurosci. Res. 69: 687-691. [Medline] [CrossRef]

3. Hokari, M., Kuroda, S., Shichinohe, H., Yano, S., Hida, K. and Iwasaki, Y. 2008. Bone marrow stromal cells protect and repair damaged neurons through multiple mechanisms. J. Neurosci. Res. 86: 1024-1035. [Medline] [CrossRef]

4. Kamishina, H., Deng, J., Oji, T., Cheeseman, J. A. and Clemmons, R. M. 2006. Expression of neural markers on bone marrow-derived canine mesenchymal stem cells. Am. J. Vet. Res. 67: 1921-1928. [Medline] [CrossRef]

5. Kawasaki, H., Suemori, H., Mizuseki, K., Watanabe, K., Urano, F., Ichinose, H., Haruta, M., Takahashi, M., Yoshikawa, K., Nishikawa, S., Nakatsuji, N. and Sasai, Y. 2002. Generation of dopaminergic neurons and pigmented epithelia from primate ES cells by stromal cell-derived inducing activity. Proc. Natl. Acad. Sci. USA 99: 1580-1585. [Medline] [CrossRef]

6. Kim, D. K., Nishida, H., An, S. Y., Shetty, A. K., Bartosh, T. J. and Prockop, D. J. 2016. Chromatographically isolated CD63 ${ }^{+}$CD81 ${ }^{+}$extracellular vesicles from mesenchymal stromal cells rescue cognitive impairments after TBI. Proc. Natl. Acad. Sci. USA 113: 170-175. [Medline] [CrossRef]

7. Lee, H., Kang, J. E., Lee, J. K., Bae, J. S. and Jin, H. K. 2013. Bone-marrow-derived mesenchymal stem cells promote proliferation and neuronal differentiation of Niemann-Pick type $\mathrm{C}$ mouse neural stem cells by upregulation and secretion of CCL2. Hum. Gene Ther. 24: 655-669. [Medline] [CrossRef]

8. Li, H., Wang, C., He, T., Zhao, T., Chen, Y. Y., Shen, Y. L., Zhang, X. and Wang, L. L. 2019. Mitochondria transfer from bone marrow mesenchymal stem cells to motor neurons in spinal cord injury rats via gap junction. Theranostics 9: 2017-2035. [Medline] [CrossRef]

9. Liu, S. and Chen, Z. 2019. Employing endogenous NSCs to promote recovery of spinal cord injury. Stem Cells Int. 2019: 1958631. [Medline] [CrossRef]

10. Lou, S., Gu, P., Chen, F., He, C., Wang, M. and Lu, C. 2003. The effect of bone marrow stromal cells on neuronal differentiation of mesencephalic neural stem cells in Sprague-Dawley rats. Brain Res. 968: 114-121. [Medline] [CrossRef]

11. Mahmood, A., Lu, D. and Chopp, M. 2004. Intravenous administration of marrow stromal cells (MSCs) increases the expression of growth factors in rat brain after traumatic brain injury. J. Neurotrauma 21: 33-39. [Medline] [CrossRef]

12. Matsubara, K., Matsushita, Y., Sakai, K., Kano, F., Kondo, M., Noda, M., Hashimoto, N., Imagama, S., Ishiguro, N., Suzumura, A., Ueda, M., Furukawa, K. and Yamamoto, A. 2015. Secreted ectodomain of sialic acid-binding Ig-like lectin-9 and monocyte chemoattractant protein-1 promote recovery after rat spinal cord injury by altering macrophage polarity. J. Neurosci. 35: 2452-2464. [Medline] [CrossRef]

13. Nakano, N., Nakai, Y., Seo, T. B., Yamada, Y., Ohno, T., Yamanaka, A., Nagai, Y., Fukushima, M., Suzuki, Y., Nakatani, T. and Ide, C. 2010. Characterization of conditioned medium of cultured bone marrow stromal cells. Neurosci. Lett. 483: 57-61. [Medline] [CrossRef]

14. Nishida, H., Nakayama, M., Tanaka, H., Kitamura, M., Hatoya, S., Sugiura, K., Suzuki, Y., Ide, C. and Inaba, T. 2011. Evaluation of transplantation of autologous bone marrow stromal cells into the cerebrospinal fluid for treatment of chronic spinal cord injury in dogs. Am. J. Vet. Res. 72: 1118-1123. [Medline] [CrossRef]

15. Nishida, H., Nakayama, M., Tanaka, H., Kitamura, M., Hatoya, S., Sugiura, K., Harada, Y., Suzuki, Y., Ide, C. and Inaba, T. 2012. Safety of autologous bone marrow stromal cell transplantation in dogs with acute spinal cord injury. Vet. Surg. 41: 437-442. [Medline] [CrossRef]

16. Nishida, H., Shoji, Y., Nakamura, M., Hatoya, S., Sugiura, K., Yamate, J., Kuwamura, M., Kotani, T., Nakayama, M., Suzuki, Y., Ide, C. and Inaba, T. 2012. Evaluation of methods for cell harvesting and the biological properties at successive passages of canine bone marrow stromal cells. Am. J. Vet. Res. 73: 1832-1840. [Medline] [CrossRef]

17. Ohta, M., Suzuki, Y., Noda, T., Ejiri, Y., Dezawa, M., Kataoka, K., Chou, H., Ishikawa, N., Matsumoto, N., Iwashita, Y., Mizuta, E., Kuno, S. and Ide, C. 2004. Bone marrow stromal cells infused into the cerebrospinal fluid promote functional recovery of the injured rat spinal cord with reduced 
cavity formation. Exp. Neurol. 187: 266-278. [Medline] [CrossRef]

18. Okuno, T., Nakayama, T., Konishi, N., Michibata, H., Wakimoto, K., Suzuki, Y., Nito, S., Inaba, T., Nakano, I., Muramatsu, S., Takano, M., Kondo, Y. and Inoue, N. 2009. Self-contained induction of neurons from human embryonic stem cells. PLoS One 4: e6318. [Medline] [CrossRef]

19. Park, H. W., Lim, M. J., Jung, H., Lee, S. P., Paik, K. S. and Chang, M. S. 2010. Human mesenchymal stem cell-derived Schwann cell-like cells exhibit neurotrophic effects, via distinct growth factor production, in a model of spinal cord injury. Glia 58: 1118-1132. [Medline] [CrossRef]

20. Penha, E. M., Meira, C. S., Guimarães, E. T., Mendonça, M. V., Gravely, F. A., Pinheiro, C. M., Pinheiro, T. M., Barrouin-Melo, S. M., RibeiroDos-Santos, R. and Soares, M. B. 2014. Use of autologous mesenchymal stem cells derived from bone marrow for the treatment of naturally injured spinal cord in dogs. Stem Cells Int. 2014: 437521. [Medline] [CrossRef]

21. Paterson, Y. Z., Kafarnik, C. and Guest, D. J. 2018. Characterization of companion animal pluripotent stem cells. Cytometry A 93: 137-148. [Medline] [CrossRef]

22. Rajan, T. S., Diomede, F., Bramanti, P., Trubiani, O. and Mazzon, E. 2017. Conditioned medium from human gingival mesenchymal stem cells protects motor-neuron-like NSC-34 cells against scratch-injury-induced cell death. Int. J. Immunopathol. Pharmacol. 30: 383-394. [Medline] [CrossRef]

23. Suemori, H., Tada, T., Torii, R., Hosoi, Y., Kobayashi, K., Imahie, H., Kondo, Y., Iritani, A. and Nakatsuji, N. 2001. Establishment of embryonic stem cell lines from cynomolgus monkey blastocysts produced by IVF or ICSI. Dev. Dyn. 222: 273-279. [Medline] [CrossRef]

24. Uccelli, A., Benvenuto, F., Laroni, A. and Giunti, D. 2011. Neuroprotective features of mesenchymal stem cells. Best Pract. Res. Clin. Haematol. 24: 59-64. [Medline] [CrossRef]

25. Vizoso, F. J., Eiro, N., Cid, S., Schneider, J. and Perez-Fernandez, R. 2017. Mesenchymal stem cell secretome: toward cell-free therapeutic strategies in regenerative medicine. Int. J. Mol. Sci. 18: E1852. [Medline] [CrossRef]

26. Wu, S., Suzuki, Y., Ejiri, Y., Noda, T., Bai, H., Kitada, M., Kataoka, K., Ohta, M., Chou, H. and Ide, C. 2003. Bone marrow stromal cells enhance differentiation of cocultured neurosphere cells and promote regeneration of injured spinal cord. J. Neurosci. Res. 72: 343-351. [Medline] [CrossRef]

27. Xin, H., Li, Y., Buller, B., Katakowski, M., Zhang, Y., Wang, X., Shang, X., Zhang, Z. G. and Chopp, M. 2012. Exosome-mediated transfer of miR-133b from multipotent mesenchymal stromal cells to neural cells contributes to neurite outgrowth. Stem Cells 30: 1556-1564. [Medline] [CrossRef]

28. Yang, J., Wu, H., Hu, N., Gu, X. and Ding, F. 2009. Effects of bone marrow stromal cell-conditioned medium on primary cultures of peripheral nerve tissues and cells. Neurochem. Res. 34: 1685-1694. [Medline] [CrossRef] 